\title{
Experimental Study on Gas Outburst Removal by Cross-seam Holes Pre-drilling Gas Drainage in Floor Roadway
}

\author{
Peng Zhang ${ }^{1, a^{*}}$ and Yongjiang Zhang ${ }^{2, b,{ }^{*}}$ \\ ${ }^{1,2}$ National Key Laboratory of Gas Disaster Detecting, Preventing and Emergency Controlling, \\ Chongqing 400037, China \\ ${ }^{1,2}$ Chongqing Research Institute of China Coal Technology \& Engineering Group, Chongqing \\ 400039, China
}

a419802281@qq.com, bzhangyj_1026@163.com

Keywords: Crossing hole; Drainage outburst elimination; Low permeability coal seam; Bottom lane; Coal lane strip

\begin{abstract}
Because of China's coal mine gas disaster is serious, for a single outburst low permeability coal seam, pre-drilling gas drainage by cross-seam holes is the main means to solving the gas disaster. Aiming at the problem of the coal roadway strip and the working face outburst removal, the experimental study on cross-seam holes pre-drilling gas drainage in floor roadway. The evolution law of gas pressure along with the extraction time is analyzed, the key parameters of the best extraction efficiency are obtained. The experiment was carried out in the test mine, The research shows that cross-seam holes pre-drilling gas drainage in floor roadway effectively solve the outburst problems without protective layer mining and single coal seam, and achieved remarkable results, the coal roadway safety belt tunneling and mining face, which plays an important role.
\end{abstract}

\section{Introduction}

In the case of no protective seam mining and single outburst dangerous coal seam, after the test of pre-drilling gas drainage is effective, must use the pre-drilling gas drainage as outburst prevention measures. The main measures of outburst prevention in coal seam driving in the coal seam are the cross-seam holes pre-drilling gas drainage in the drilling area[1.2], the application of these measures to prevent sudden and comprehensive treatment of the gas well, but in practical application, the original coal seam permeability and the extraction rate are very low, directly affect the comprehensive management of drainage the effect of gas. Because the permeability of coal seam is one of the main factors influencing the effect of gas drainage, especially for low permeability and high gas coal seam, if it can take effective technical means to improve the permeability of the coal seam, It were be the best way to improve the pre drainage effect of coal seam gas[3.4.5].

\section{Coal Seam Gas Pressure Distribution around Borehole}

This experiment is based on the $\mathrm{C}_{13}$ coal seam of cross-hole coal seam, the coal seam gas content coefficient takes the measured value $9.8 \mathrm{~m}^{3} /\left(\mathrm{m}^{3} \cdot \mathrm{MPa}^{0.5}\right)$, measured value of gas pressure in coal seam 3.1MPa, the permeability coefficient of coal seam is the original place of the measured value of $7.22 \times 10^{-2} \mathrm{~m}^{2} /\left(\mathrm{MPa}^{2} \mathrm{~d}\right)$, negative pressure drainage $39.5 \mathrm{kPa}$. The distribution of gas pressure in coal seam around the original coal seam is analyzed numerically (show Fig.1). $\mathrm{C}_{13}$ coal mine test numerical simulation results show that the permeability of coal seam is the main factor affecting borehole mining area, the permeability coefficient is larger, the influence range of the drainage holes is large; the original low permeability coal seams $\left(7.22 \times 10^{-3} \mathrm{~m}^{2} /\left(\mathrm{MPa}^{2} . \mathrm{d}\right)\right), 30 \mathrm{~d}$ in the extraction time, the flow field influence range of only $4 \mathrm{~m}$; if the coal seam permeability coefficient increased by 10 times, the flow impact range will reach $9.6 \mathrm{~m}$; if the coal seam permeability coefficient increased by 100 times, the flow impact range will reach 19m; coal seam permeability is bigger, the flow field within the gas pressure gradient is smaller, the greater amount of gas drainage. The permeability 
coefficient of coal seam and the content of certain specific coefficients, although the original gas pressure of coal seam is different in different places, but if the same drainage time, drainage hole around the coal gas and the dimensionless gas pressure distribution is the same; the $\mathrm{C}_{13}$ of low permeability coal seam, in the first three months of drainage $(90 \mathrm{~d})$ of the total amount of drainage pumping more than $90 \%$ of the amount of. After $120 \mathrm{~d}$, with the extension of extraction time, extraction rate will increase production is very small, when the extraction time was $150 \mathrm{~d}$, the basic stability of gas pressure distribution around the coal mining borehole, the flow has very small pumping drilling; therefore, the low permeability coal seam, the original effective drainage time for $120 \mathrm{~d}$, then extended drainage time will have no practical significance, which is of low permeability coal seam primitive drainage has a limit drainage time problem[6.7].

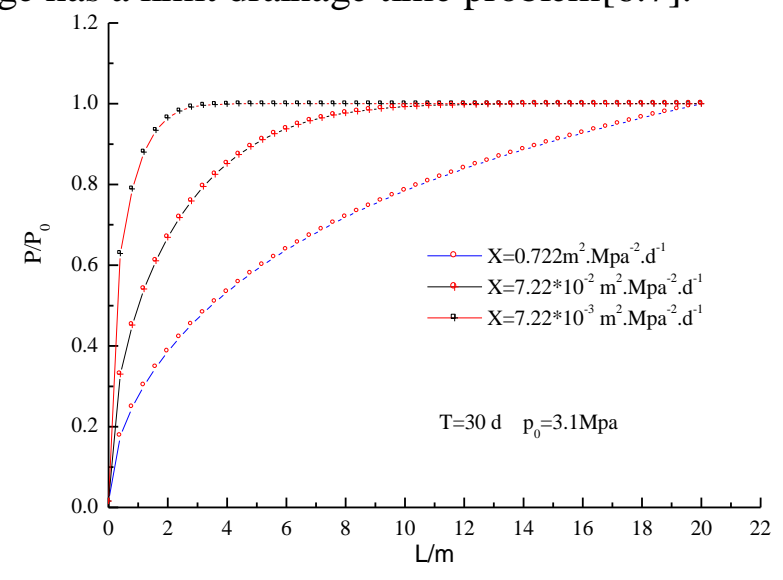

Figure 1. Distribution of gas pressure in coal seam around coal seam under different permeability coefficient under the condition of $\mathrm{T}=30 \mathrm{~d}$

\section{Coal Seam Gas Drainage Rate}

The extraction rate of the gas drainage borehole is defined as follows: the ratio of the total amount of gas extracted from two adjacent boreholes and the ratio of the total amount of the original gas in the coal seam in the two mining area should be taken into account. The numerical calculation of the extraction rate of the coal seam with different permeability coefficient in the different hole spacing is shown in fig. 2.

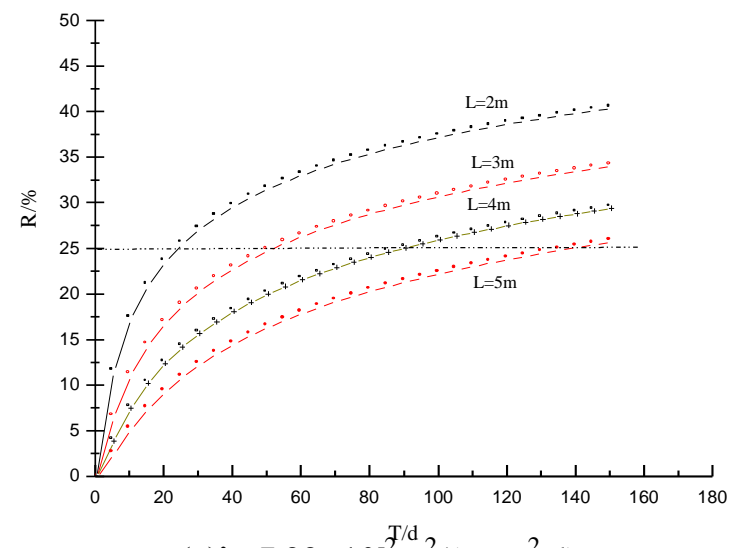

(a) $\lambda=7.22 \times 10^{-2 / \mathrm{d}} \mathrm{m}^{2} /\left(\mathrm{MPa}^{2} . \mathrm{d}\right)$ 


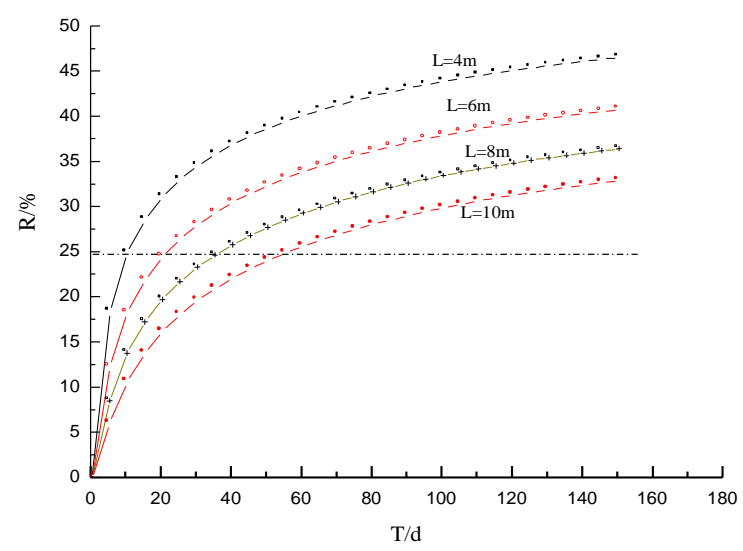

(b) $\lambda=0.722 \mathrm{~m}^{2} /\left(\mathrm{MPa}^{2} . \mathrm{d}\right)$

Figure 2. Coal seam gas extraction rate under different drilling spacing

The numerical results show that the test of coal mine lambda $\left.=(3-8) \times 10^{-2} \mathrm{~m}^{2} /\left(\mathrm{MPa}^{2} . \mathrm{d}\right)\right)$, extraction rate of $30 \%$ effective prevention measures standard, when the extraction time was $30 \mathrm{~d}$, the drainage radius $1 \mathrm{~m}$, drainage borehole spacing is $2 \mathrm{~m}$; when the gas drainage hole the spacing is $3 \mathrm{~m}$, the extraction time should be greater than $50 \mathrm{~d}$; when the drainage hole spacing is $4 \mathrm{~m}$, the extraction time should reach $90 \mathrm{~d}$; when the drainage hole spacing is $5 \mathrm{~m}$, the extraction time should reach $150 \mathrm{~d}$; when the drainage hole spacing is greater than $5 \mathrm{~m}$, even if the drainage time is over 150 d, up to effectively prevent the cross-hole coal to eliminate the hazard of coal and gas outburst 30\% drainage rate standard. If the permeability coefficient of coal seam is increased by 10 times, in the $60 \mathrm{~d}$ extraction time, the extraction hole spacing is arranged as $8 \mathrm{~m}$.

\section{Experimental Study on Gas Outburst Removal by Pre-drilling and Gas Drainage in the Bottom Seam}

Test Area Overview. 1482 (3) coal seam down two mining area is located in the West Mountain West Wing, $-700 \mathrm{~m}$ contour to the south, $\mathrm{Xi}$ exploration line to the west, the working surface elevation of $-730 \mathrm{~m} \sim-760 \mathrm{~m}, 13-1$ coal seam excavation working face, coal seam thickness was $3.7 \mathrm{~m}$, the gas content of $9.5 \mathrm{~m} 3 / \mathrm{t}, 4 \mathrm{Mpa}$ gas pressure, the permeability coefficient of coal seam measured $6.20 \times 10-2 \mathrm{~m} 2 /(\mathrm{MPa} 2 \mathrm{~d})$. In the outburst danger area. Roadway design length $415 \mathrm{~m}$, width $4.6 \mathrm{~m}$, width $5.0 \mathrm{~m}$, height $3.0 \mathrm{~m}$, net section $14.4 \mathrm{~m} 2$.

Study on the Extraction Effect of Through Hole Drilling. Fig. 3 is 1482 (3) floor No. 16 Lane No. 3 drilling field changes of single hole drainage borehole flow can be seen from the chart, beginning with stubble drainage volume, drainage rate of borehole $3 \mathrm{is} 45 \mathrm{~L} / \mathrm{min}$ in the initial $10 \mathrm{~d}$ range, drainage flow and rapid attenuation of drilling the extraction of $10 \mathrm{~d}$, gas flow is reduced to $20 \mathrm{~L} / \mathrm{min}$ drainage borehole, then decreased relatively smooth drainage after $81 \mathrm{~d}$, the gas flow is $6 \mathrm{~L} / \mathrm{min}$ single hole pumping $[8,9,10]$.

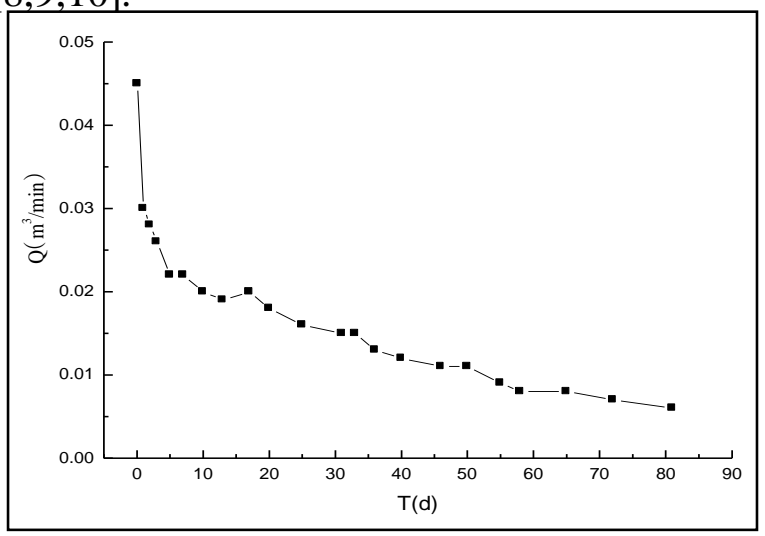

Figure 3. The change of gas flow rate and extraction time of single hole drainage in through hole drilling 
In the process of drilling and drainage, the gas hole is used to measure the single hole drainage of the well drilling, and the measured results are converted to 100 meters of borehole.

$$
q=q_{0} e^{-\beta t}
$$

In this formula:

$q_{0}$ - - -borehole initial drainage gas flow rate, $\mathrm{m}^{3} / \mathrm{m} . \mathrm{d}$;

$\beta^{--}$borehole drainage gas flow attenuation coefficient, $\mathrm{d}^{-1}$;

$\mathrm{t}$ - - extraction time, $\mathrm{d}$;

q - - borehole drainage gas flow rate, $\mathrm{m}^{3} / \mathrm{m} . \mathrm{d}$.

Therefore, the negative exponential function is used for regression analysis. According to the measured data of single hole flow, the flow rate and its regression curve of 100 meters drilled in the more serious danger area are shown in figure 3:

$$
q=347.98 \cdot e^{-0.02 t} \text {. }
$$

The formula of Eq. 2 (time) $t$ integration is used to obtain the formula of gas extraction volume of 100 meters borehole:

$$
Q=17448.75 \times\left(1-e^{-0.02 t}\right) \text {. }
$$

According to the analysis of the previous evaluation, the outburst danger can be eliminated when the gas pre drainage rate exceeds $30 \%$. Therefore, the effective radius of borehole extraction can be calculated by the following formula:

$$
100 \times\left(\pi R^{2}\right) \gamma W \times 30 \%=Q .
$$

In this formula:

$\mathrm{R}$ - -the effective drainage radius of the drilled hole, $\mathrm{m}$;

$\mathrm{m}$ - - coal seam thickness, m;

$\gamma-$ - coal bulk density, $\mathrm{t} / \mathrm{m}^{3}$;

$W--\mathrm{m}^{3} / \mathrm{t}$

At the same time (Eq. 3, Eq. 4) two type, can get effective drilling drainage radius R:

$$
R=\sqrt{\frac{17448.75 \times\left(1-e^{-0.02 t}\right)}{30 \cdot \pi \gamma W}}
$$

When the pre-drilling gas drainage time is 3 months, the effective drainage radius is $3.1 \mathrm{~m}$.

After 5 months of the pre-drilling gas drainage, the total amount of gas extraction through the hole in the bottom seam roadway is 70 thousand and $800 \mathrm{~m}^{3}$. The gas extraction rate is $31.5 \%$ of the the pre-drilling gas drainage area $\left(224\right.$ thousand and $\left.800 \mathrm{~m}^{3}\right)$, and the gas extraction rate is more than $30 \%$ in the the pre-drilling gas drainage area, so as to achieve the purpose of eliminating outburst.

Effect of Pre-drainage Gas to Outburst Removal in Floor Roadway. Based on the 1482 (3) coal seam dip driving process tracking study in $1400 \mathrm{~m}$ tunneling process, take long borehole drilling and head-on discharge driving while pumping local outburst prevention measures, Smax $=4.5 \mathrm{Kg} / \mathrm{m}$ prediction of outburst danger index, initial velocity of gas emission is $1.5 \mathrm{~L} / \mathrm{min}$. When the air flow rate of $630 \mathrm{~m}^{3} / \mathrm{min}$ is $0.27 \%$, the gas concentration is the highest. In $40 \mathrm{~m}-220 \mathrm{~m}$ to take the floor roadway pre-drilling gas drainage mining technology section of the tunnel, when the coal roadway excavation, only the 8-10 discharge holes, there was no outburst index exceeding the normal airflow, and the gas concentration was less than $0.25 \%$; after entering the $220 \mathrm{~m}$ of the original coal, take driving while pumping technical measures in coal roadway when the return air gas concentration rises rapidly, return air gas concentration in $0.4 \%-0.5 \%$. The $325 \mathrm{~m}-415 \mathrm{~m}$ section on the bottom layer of pre-drilling gas drainage hole area, no gas and abnormal phenomenon, the monthly tunneling footage in more than $200 \mathrm{~m}$. Therefore, in serious outburst coal seam excavation 
working face, the dense gas pre-drilling gas drainage by crossing boreholes to strip regional outburst, not only reduces the risk of outburst in heading face, reduce the amount of gas emitted from the tunnel excavation process and reduce dust, but also greatly improves the driving speed.

\section{Conclusions}

1. Study on the original coal extraction distribution around the borehole coal gas pressure, coal seam permeability is the main factor affecting borehole mining area; test of low permeability coal seam, the total amount of more than $90 \%$ pumping in the first three months of the drainage drainage quantity, after $120 \mathrm{~d}$, with the extension of extraction time, extraction rate will increase production is very small, the low permeability coal seam drainage parameters.

2. In severe outburst coal seam excavation working face, the dense gas pre drainage by crossing boreholes to strip regional outburst coal seam drilling test, pre drainage time was 3 months, drilling drainage radius is $3.1 \mathrm{~m}$, the excavation roadway safety $1400 \mathrm{~m}$, the highest $200 \mathrm{~m}$ per month, reducing the risk of outburst in heading the surface, greatly improves the driving speed.

\section{Acknowledgments}

This work was financially supported by the National Key Research and Development Program of China (2017YFC0804206), Coal science research institute of science and technology innovation fund projects (2016ZYMS016).

\section{References}

[1] L. Yuan, B.Q. Lin and W. Yang (2015) "Research Progress and Development Direction of Gas Control with Mine Hydraulic Technology in China Coal Mine," Coal Science and Technology. J., (01): 45-49.

[2] X.H. Li, X.C. Wang and Y. Kang, et al (2014) "Energy Characteristic and Dissipation in Transient Process of Hydraulic Cutting Seams System in Coal Seam," Journal of China Coal Society. J., (08): 1404-1408.

[3] Y. Liu, Y.Y. Lu and X.H. Li, et al (2010) "Application of Drilling in Roof or Floor with High Pulse Pressure Water Jet to Improve Gas Drainage," Journal of China Coal Society. J., (7): 1115-1119.

[4] Z.J. Fan, J.M. Zhang and H.S. Yuan, Water Physical-Mechanical Properties of Silty Mudstone of Badong Formation, The Electronic Journal of Geotechnical Engineering, Volume 20 [2015] Bundle 3.

[5] X.Z. Meng, J.J. Cao and Q. He, et al (2009) "Study and Application on Hydraulic Highly Efficient Outburst Prevention Integration Technology," Mining Safety and Environmental Protection. J., (S1): 49-53.

[6] J.Q. Cao, X.Z. Meng and Q. He, et al (2009) "New Drilling and Reaming Integrated Technology with Hydraulic Outburst Prevention," Coal Science and Technology. J., 39(11): 4044.

[7] M.B. Chi (2015) "Experimental Study on Hydraulic Cutting Seam Prevention and Cure of Xinzhouyao Mines Rock Burst," Shan Xi: Tai Yuan University of Technology. D.

[8] C.S. Zheng, B.Q. Lin and W.Yang, et al (2014) "Hole-spraying Mechanism of Hydraulic Slotting Drilling and the Influence of Slotting Mode," Safety in Coal Mines. J., (01): 5-8+12.

[9]X.P. Xin, J.Y. Zhang and Z.F. Wang (2014) "Application of Pressure Relief and Permeability Increasing Technology with Rotating Slice Cutting Through Seam in Jiulishan Coal Mine," Safety in Coal Mines. J., (12): 83-84+88.

[10] L.Y. Yu(2016) 'Hydraulic Cutting Technology Control in High Gassy Seam,”. Inner Mongolia Coal Economy. J., (01): 90-91+128. 